\title{
RELEITURA À APLICABILIDADE DO "DANO SOCIAL" NAS RELAÇÕES DE CONSUMO
}

\author{
Maria Cláudia da Silva Antunes de Souza ${ }^{1}$ \\ Ana Luiza Colzani ${ }^{2}$
}

RESUMO: O presente artigo tem como objeto de estudo o Dano Social, com objetivo de caracterizá-lo como instrumento capaz de sobrepor um dos obstáculos enfrentados para o difícil equilíbrio entre consumidor e fornecedor: a valoração do dano moral e sua destinação; de forma que não ocorra nem o enriquecimento indevido, nem o estímulo à repetição da conduta pela ínfima quantia arbitrada. O relato dos resultados é metodologicamente composto na base lógica-indutiva, enquanto que, para a pesquisa, são utilizadas as técnicas do Referente, da Categoria, do Conceito Operacional e da Pesquisa Bibliográfica.

PALAVRAS-CHAVE: Dano Social. Danos difusos. Consumidor. Responsabilidade civil. Fundo de Direitos

\section{RELEASE OF THE APPLICABILITY OF "SOCIAL DAMAGE" IN CONSUMER RELATIONS}

\begin{abstract}
The purpose of this article is to study Social Damage, aiming to characterize it as an instrument capable of overcoming one of the obstacles faced for the difficult balance between consumer and supplier: the valuation of moral damage and its destination; so that neither improper enrichment nor the stimulus to the repetition of the conduct by the small amount arbitrated occurs. The results report is methodologically based on the logic-inductive basis, whereas for the research, the techniques of Referent, Category, Operational Concept
\end{abstract}

\footnotetext{
${ }^{1}$ Doutora e Mestre em "Derecho Ambiental y de la Sostenibilidad" pela Universidade de Alicante - Espanha. Mestre em Ciência Jurídica pela Universidade do Vale do Itajaí - Brasil, Graduada em Direito pela Universidade do Vale do Itajaí - Brasil. Professora Permanente no Programa de Pós-Graduação Stricto Sensu em Ciência Jurídica, nos cursos de Doutorado e Mestrado em Direito e na Graduação no Curso de Direito da Universidade do Vale do Itajaí - UNIVALI. Coordenadora do Grupo de Pesquisa "Direito Ambiental, Transnacionalidade e Sustentabilidade" cadastrado no CNPq/EDATS/UNIVALI. Coordenadora do Projeto de pesquisa aprovado no CNPQ intitulado: "Possibilidades e Limites da Avaliação Ambiental Estratégica no Brasil e Impacto na Gestão Ambiental Portuária" (2013/2015). Coordenadora do Projeto de pesquisa aprovado através do Edital MCTI/CNPQ/UNIVERSAL 14/2014, intitulado "Análise comparada dos limites e das possibilidades da Avaliação Ambiental Estratégica e sua efetivação com vistas a contribuir para uma melhor gestão ambiental da atividade portuária no Brasil e na Espanha" (2015/2017). Coordenadora do Projeto de pesquisa aprovado através da FAPESC - EDITAL 09/2015- intitulado "Limites e possibilidades da Avaliação Ambiental Estratégica e sua efetivação com vistas a contribuir para uma melhor Gestão Ambiental da Atividade Portuária Catarinense". (2016/2018). Membro vitalício à Cadeira n. 11 da Academia Catarinense de Letras Jurídicas (ACALEJ). Membro Efetivo do Instituto dos Advogados Brasileiros (IAB). Membro da Comissão de Direito Ambiental do IAB (2016/2018). Advogada e consultora jurídica.

${ }^{2}$ Doutoranda e Mestre pelo Programa de Pós-graduação Stricto Sensu em Ciência Jurídica PPCJ UNIVALI (CAPES - Conceito 5), com bolsa do Programa de Suporte à Pós-Graduação de Instituições Comunitárias de Ensino Superior (PROSUC-CAPES). Mestre em Máster Universitario en Derecho Ambiental y de la Sostenibilidad na Universidad de Alicante, Espanha. Bacharel em Direito pela Universidade do Vale do Itajaí UNIVALI (2014). Possui graduação em Publicidade e Propaganda pela Universidade do Vale do Itajaí (2009). Advogada com inscrição número 40.294 OAB/SC.
} 
and Bibliographic Research are used.

KEY-WORDS: Social Damage. Diffuse damages. Consumer. Civil responsability. Fund of rights

\section{INTRODUÇÃO}

A profunda transformação social ocorrida ao longo dos últimos séculos, através do desenvolvimento das economias de massa, mostrou a insuficiência da tutela dos interesses individuais para os novos desafios da contemporaneidade.

Os números trazidos nesse trabalho, através da coleta e análise de dados do Conselho Nacional de Justiça (CNJ), confirmam que o judiciário precisa de novas ferramentas para lidar com as crescentes demandas consumeristas. Algo está a incentivar, ou pelo menos não está a coibir, as más condutas no mercado de consumo.

Questiona-se, então, de que forma pode ser aplicado o Dano Social, enquanto direito difuso, em uma ação individual de consumo, com o objetivo de reequilíbrio das relações consumeristas.

Desta forma, o presente artigo tem como objeto de estudo o Dano Social, com objetivo de caracterizá-lo como instrumento capaz de sobrepor um dos obstáculos enfrentados para o difícil equilíbrio entre consumidor e fornecedor: a valoração do dano moral e sua destinação; de forma que não ocorra nem o enriquecimento indevido, nem o estímulo à repetição da conduta pela ínfima quantia arbitrada.

Para tanto, divide-se o trabalho em três partes: na primeira, trata-se da individualização à necessária coletivização do direito do consumidor; na segunda busca-se delimitar quais são as tutelas coletivas de direitos, bem como os direitos coletivos, contemplando, também, os "novos danos", quais sejam, o dano moral coletivo e o dano social; e finalmente, na terceira parte, enquadra-se o Dano Social como instrumento capaz de reequilibrar as relações de consumo com aplicação tanto nas ações coletivas quanto individuais de consumo.

O relato dos resultados é metodologicamente composto na base lógica-indutiva, enquanto que, para a pesquisa, são utilizadas as técnicas do Referente, da Categoria, do Conceito Operacional e da Pesquisa Bibliográfica (PASOLD, 2011, p. 197-209). 


\section{DA TUTELA INDIVIDUAL À COLETIVA NA PROTEÇÃO DOS DIREITOS DO CONSUMIDOR}

A partir da evolução dos direitos individuais, tais quais postos no processo civil tradicional, em que os litígios se baseavam nos interesses individuais dos próprios lesados; para os direitos difusos, que atingem uma coletividade de pessoas, determináveis ou não; buscou-se também novas soluções procedimentais.

Como, em muitos casos, não se pode precisar quantos são os potenciais adquirentes e usuários de produtos e de serviços, bem como o alcance dos danos trazidos à sociedade, somente é possível alcançar a efetiva proteção do consumidor por meio de ação preventiva e coibitória em relação aos maus fornecedores. E, para tanto, o Código de Defesa do Consumidor, em seu artigo 83, estabeleceu para os direitos ali previstos quaisquer espécies de demandas capazes de propiciar sua ampla e adequada tutela, de forma individual ou coletiva.

Assim, a ideia tradicional do processo civil, em que as tutelas se destinavam exclusivamente às partes que buscam seus próprios interesses individuais em juízo, não encontrou guarita para a proteção dos direitos difusos que emergiram. Esses "novos" direitos pertencem a um grupo, ao público em geral ou a um segmento de público, para os quais as regras de legitimidade, normas de procedimento e atuação judicial não se destinavam (CAPELLETTI, 1998, p. 49-50).

Enquanto direito de terceira dimensão ${ }^{3}$, ou ainda denominado de direito transindividual $^{4}$, isto é, direitos que são de várias pessoas, mas não pertencem a ninguém isoladamente; transcendem o indivíduo isoladamente considerado (BONAVIDES, 2006, p.569).

\footnotetext{
${ }^{3}$ Quanto à nomenclatura, "em que pese o dissídio na esfera terminológica, verifica-se crescente convergência de opiniões no que concerne à idéia que norteia a concepção das três (ou quatro, se assim preferirmos) dimensões dos direitos fundamentais, no sentido de que estes, tendo tido sua trajetória existencial inaugurada com o reconhecimento formal nas primeiras Constituições escritas dos clássicos direitos de matriz liberal-burguesa, se encontram em constante processo de transformação, culminando com a recepção, nos catálogos constitucionais e na seara do Direito Internacional, de múltiplas e diferenciadas posições jurídicas, cujo conteúdo é tão variável quanto as transformações ocorridas na realidade social, política, cultural e econômica ao longo dos tempos"”. SARLET, 2015, p. 55.

4 “Assim sendo, a teoria dimensional dos direitos fundamentais não aponta, tão-somente, para o caráter cumulativo do processo evolutivo e para a natureza complementar de todos os direitos fundamentais, mas afirma, para além disso, sua unidade e indivisibilidade no contexto do direito constitucional interno e, de modo especial, na esfera do moderno 'Direito Internacional dos Direitos Humanos"'. SARLET, 2015, p. 55.
} 
Assim, "os direitos do consumidor compõem um direito social que é ao mesmo tempo categorial e difuso" (BARROS, 2018), pois, apesar de restringir a um grupo - de consumidores - é, na prática, irrestrito, visto que protege uma categoria tão ampla que não possibilita a exclusão de nenhum indivíduo.

No Brasil, a práxis da tutela coletiva intensificou-se a partir de 1981, após a lei da política nacional do meio ambiente, posteriormente, “a Lei 7.347, de 1985, estabeleceu um instrumental jurisdicional mais contemporâneo para a responsabilização do dano ambiental coletivo" (LEITE, 2000, p. 181-182).

Em sequência, a Constituição da República Federativa do Brasil de 1988 destinou diversos dispositivos às proteções difusas, como o direito ambiental e consumerista. Abriu-se, então, através de seus princípios e garantias fundamentais, prerrogativas para criação de instrumentos de jurisdição coletiva em outros diplomas (LEITE, 2000, p. 181-182).

Tal leitura constitucional da coletivização do processo como meio renovatório de acesso à Justiça condiz com a compreensão das ondas renovatórias propostas por Cappelletti e Garth (1998). Nesse estudo, apontam os autores ao menos três ondas renovatórias de acesso à justiça, dentre elas a representação dos interesses difusos, pois,

[...] o direito ao acesso efetivo tem sido progressivamente reconhecido como sendo de importância capital entre os novos direitos individuais e sociais, uma vez que a titularidade de direitos é destituída de sentido, na ausência de mecanismos para sua efetiva reivindicação. $\mathrm{O}$ acesso à justiça pode, portanto, ser encarado como o requisito fundamental o mais básico dos direitos humanos — de um sistema jurídico moderno e igualitário que pretenda garantir, e não apenas proclamar os direitos de todos (CAPELLETTI, 1998, p. 5).

$\mathrm{O}$ acesso à justiça como o modo pelo qual os direitos se tornam efetivos, preocupa-se com modelos processuais mais amplos que correspondam com as expectativas dos direitos transindividuais. Esses, por sua vez, se distinguem por serem "indeterminados pela titularidade, indivisíveis com relação ao objeto, colocados no meio do caminho entre os interesses públicos e os privados" (GRINOVER, 2008, p. 229), típicos dos conflitos da sociedade massificada, "carregados de relevância política e capaz de transformar conceitos jurídicos estratificados, como a responsabilidade civil pelos danos causados no lugar da responsabilidade civil pelos prejuízos sofridos" (GRINOVER, 2008, p. 229). Ainda, a legitimação, a coisa julgada, o papel do juiz e do Ministério Público tomam novas dimensões, bem como o "o próprio sentido da jurisdição, da ação, do processo" (GRINOVER, 2008, p. 
229).

Ainda que haja uma massificação dos problemas advindos nas relações de consumo e uma solidariedade distributiva dos danos, tem-se grande procura das tutelas individuais, e não coletivas. Ou seja, têm-se problemas massificados sendo tratados de forma não massificada.

O resultado são os assombrosos números de inchaço do judiciário brasileiro. Do último relatório disponível do Conselho Nacional de Justiça (CNJ, 2017), com coleta de dados durante o ano de 2016, constata-se que o item "Direito do Consumidor Responsabilidade do Fornecedor/Indenização por Dano Moral” foi naquele ano a segunda maior demanda do poder judiciário estadual, com 1.760.905 de ações ajuizadas.

Ao restringir a avaliação apenas aos Juizados Especiais Estaduais, têm-se as demandas de consumo em primeiro lugar, com 1.234 .983 processos relacionados a "reponsabilidade do fornecedor/indenização por dano moral" $(15,15 \%)$ e em quinto lugar com 268.834 ações para "reponsabilidade do fornecedor/indenização por dano material" (3,3\%). O relatório revela problemas que vão da alta taxa de congestionamento à falta de estrutura e de pessoal no poder judiciário.

De um lado tem-se o reclame dos fornecedores de que se instaurou no Brasil uma "indústria do dano moral". Por outro, tem-se o reclame dos consumidores que não encontram outra forma de ver seu direito resguardado senão através do judiciário. O fato é que milhares de ações são propostas todos os dias versando sobre a temática consumerista e parece não surtir efeito pedagógico nos fornecedores, visto a reincidência das práticas. A partir dessa constatação, “[...] as empresas somente investirão na diminuição de falhas de seus serviços até o montante em que cheguem a um grau ótimo de danos, isto é, até o limite em que o ganho em diminuição de danos compense o valor empregado na melhora dos serviços" (PUTARCO, 2012, p. 127).

No entanto, como resolver esse impasse entre a tutela individual e a coletiva; o dano não pedagógico e o enriquecimento ilícito? Uma interpretação mais ampla dos instrumentos de proteção e defesa coletiva parece ser uma importante forma de tornar o judiciário mais célere, a medida em que uma única ação coletiva tem o poder de suprir a demanda de milhares de pessoas em um só instrumento.

E é através do Código de Defesa do Consumidor, com aplicabilidade não apenas 
na proteção dos consumidores, mas também, de modo geral, às tutelas metaindividuais, que se tem a classificação dos interesses difusos, coletivos e individuais homogêneos, no seu artigo 81, parágrafo único; os quais serão tratados a seguir.

\section{DIREITOS COLETIVOS}

Os direitos coletivos, lato sensu, compreendem uma categoria composta por direitos coletivos stricto sensu, e direitos difusos. Direitos difusos são aqueles indivisíveis que ligam circunstancialmente pessoas indeterminadas ${ }^{5}$. Ou seja, são as características de indivisibilidade e de indeterminação de quem são exatamente os lesados, que os define como tais. Já os direitos coletivos, stricto sensu, são aqueles cujos titulares podem ser determinados por um grupo, categoria ou classe de pessoas, interligados através de uma relação jurídica base $^{6}$.

Diferenciam-se, assim, da categoria anterior, a medida em que nos direitos difusos não há vínculo jurídico prévio, e sim meras circunstâncias de fatos; enquanto que, para a classificação dos direitos coletivos, é necessária uma prévia relação jurídica-base entre os titulares e a parte contrária (GIDI, 1995, p. 24).

Portanto, os interesses difusos e coletivos se assemelham pela indivisibilidade do objeto, o que os caracteriza como supraindividuais, ao passo que os direitos individuais homogêneos ${ }^{7}$, como se verá a seguir, pertencem a pessoas determinadas e são divisíveis, sendo considerados direitos supraindividuais apenas no plano processual.

Assim, como classificou Zavaski (1995, p. 33), quando se trata de tutelas coletivas fala-se do modo de defesa dos direitos difusos, coletivos e individuais homogêneos. No entanto, ao falar de tutela de direitos coletivos, restringe-se aos direitos difusos e coletivos stricto sensu.

\footnotetext{
${ }^{5}$ Art. 81, parágrafo único, I - interesses ou direitos difusos, assim entendidos, para efeitos deste código, os transindividuais, de natureza indivisível, de que sejam titulares pessoas indeterminadas e ligadas por circunstâncias de fato.

${ }^{6}$ Art. 81, parágrafo único, II - interesses ou direitos coletivos, assim entendidos, para efeitos deste código, os transindividuais, de natureza indivisível de que seja titular grupo, categoria ou classe de pessoas ligadas entre si ou com a parte contrária por uma relação jurídica base.

${ }^{7}$ Art. 81, parágrafo único, III - interesses ou direitos individuais homogêneos, assim entendidos os decorrentes de origem comum.
} 
O sistema jurídico brasileiro admite, de forma expressa, a tutela dos direitos de massa, inserindo-os no rol de direitos fundamentais e a reconhece desde a Lei da Ação Popular de 1965, ratificada pela Lei da Política Nacional do Meio Ambiente de 1981, pela Lei da Ação Civil Pública de 1985, além do já citado Código de Defesa do Consumidor de 1990 entre outros diplomas legais. Assim, a reparação integral do dano consagrar-se-ia de forma ampla, como salientou Grinover (2008, p.229), não apenas na responsabilidade civil pelos danos causados, mas pela responsabilidade civil pelos prejuízos sofridos.

Essa nova perspectiva, qual seja, a do ofensor e não da vítima, é de fundamental importância para diferir o caráter de punição da mera reparação na teoria dos danos, como se verá no item 3.

Já os direitos homogêneos, ao contrário dos direitos coletivos ou difusos, não são materialmente transindividuais, mas guardam dentro da sua individualidade características idênticas ou muito semelhantes, pertencentes a uma massa de sujeitos. Essa homogeneidade admite tutela coletiva por meio de uma única ação, e seu resultado pode ser repartido entre as partes em porções determinadas pelo prejuízo experimentado por cada componente.

Por exemplo, quando vendido produto com menor quantidade do que anunciado, cada lesado, individualmente, poderia acessar ao judiciário em busca de reparação. Ou, ainda, em uma ação coletiva buscando a tutela individual homogênea, todos os interessados poderiam ser parte em busca de sua quota do prejuízo.

Essa tutela está conectada à ideia de interesses que, individualmente, seriam mitigados pelo baixo valor, mas que, em conjunto, ganham densidade. Ou ainda interesses que, por sua vez, ganham maior eficiência quando agrupados do que individualmente processados, por ressaltar a reiteração da conduta ilícita do agente ofensor.

Essas são as formas coletivas de se processar judicialmente algumas espécies de danos. Importante também abranger materialmente os chamados "novos danos"8 em específico duas espécies: os danos morais coletivos e o dano social.

A abertura da teoria da responsabilidade civil rumo à coletivização substitui o conceito de ato ilícito pelo de dano injusto, ampliando as possibilidades de incidência (BITTAR FILHO, 1994, p. 60).

\footnotetext{
${ }^{8}$ Em oposição aos danos tradicionais: dano patrimonial e dano moral individual.
} 
É nesse processo de ampliação de seus horizontes que a responsabilidade civil encampa o dano moral coletivo, aumentando as perspectivas de criação e consolidação da uma ordem jurídica mais justa e eficaz. Conceituado como a injusta lesão da esfera moral de uma dada comunidade, o dano moral coletivo é produto de ação que toma de assalto a própria cultura, em sua faceta imaterial (BITTAR FILHO, 1994, p. 60).

Assim, dano moral coletivo é aquele de natureza extrapatrimonial que corresponde a uma lesão injusta e intolerável de um direito ou interesse dos quais é titular determinada categoria de pessoas (MEDEIROS NETO, 2007, p. 137). Prescinde, no entanto, de comprovação de dor, pois inaplicável no contexto coletivo.

Para sua comprovação e mensuração devem ser observados alguns pressupostos, como a conduta antijurídica; a ofensa a interesses jurídicos fundamentais, de natureza extrapatrimonial, titularizados por uma determinada coletividade; a intolerabilidade da ilicitude e o nexo causal entre conduta e o dano (MEDEIROS NETO, 2007, p. 136).

Ou seja, é a lesão injusta o parâmetro, e não necessariamente suas consequências, impossíveis de mensurar no âmbito coletivo, e daí sua proximidade com o punitive damages: por se tratar de claro caso em que punir o ofensor é mais importante do que a perspectiva da vítima em ser ressarcida.

O dano moral coletivo foi apenas recentemente pacificado no âmbito do Superior Tribunal de Justiça ${ }^{9}$, inclusive com fundamento no código consumerista, com a ressalva de que "é preciso que o fato transgressor seja de razoável significância e desborde os limites da tolerabilidade. Ele deve ser grave o suficiente para produzir verdadeiros sofrimentos, intranquilidade social e alterações relevantes na ordem extrapatrimonial coletiva" (RECURSO ESPECIAL 1.221.756/RJ.).

Já o dano social, categoria de danos objeto deste trabalho, foi delimitado pela primeira vez por Azevedo (2004, p. 376), como sendo "lesões à sociedade, no seu nível de vida, tanto por rebaixamento de seu patrimônio moral - principalmente a respeito da segurança - quanto por diminuição na qualidade de vida"

Seriam passíveis de reparação por danos sociais os atos negativamente exemplares, nas mais diversas esferas cíveis, que causam um rebaixamento do nível coletivo

\footnotetext{
${ }^{9}$ REsp 1.397.870/MG. Predecentes: EDcl no AgRg no AgRg no REsp 1.440.847/RJ; REsp 1.269.494/MG; REsp 1.367.923/RJ; REsp 1.197.654/MG.
} 
de vida, especificadamente da qualidade, sendo condutas socialmente reprováveis, e, portanto, passíveis da reparação especial.

O dano social representa a aplicação da função social da responsabilidade civil e se diferencia do dano moral coletivo enquanto este tem como destinatário final a vítima, que é pessoa determinada ou determinável, enquanto os danos sociais buscam a tutela de pessoas indeterminadas ou indetermináveis.

Os danos sociais são causa, pois, de indenização punitiva por dolo ou culpa grave, especialmente, repetimos, se atos que reduzem as condições coletivas de segurança, e de indenização dissuasória, se atos em geral de pessoa jurídica, que trazem uma diminuição do índice de qualidade de vida da população (AZEVEDO, 2004, p. 382).

Encaixa-se, por oportuno, aos danos difusos nas relações de consumo, em que o princípio da "boa-fé objetiva" regula todo o microssistema, e, por conseguinte, infrações a ele ferem o nível de credibilidade, confiança e segurança, necessários ao justo equilíbrio nas relações consumeristas.

Neste sentido, o Código de Defesa do Consumidor prevê a responsabilidade objetiva, independente de culpa. Não se diferencia, de qualquer modo, duas empresas, a exemplo, que tenham colocado no mercado medicamento que acabou por gerar graves danos à saúde de consumidor; sendo que a primeira agiu com prudência e tomou todas as medidas que pensava ser necessária; enquanto a segunda agiu com negligência e o fez para obtenção de maior lucro. Neste caso, restaria ao quantum do dano social refletir o "grau de culpabilidade" ou de "reprovabilidade" da conduta.

$\mathrm{Na}$ seara da reparação civil, enquanto ação individual de consumo, ter-se-ia, então, além do dano patrimonial individual, como danos emergentes ou lucros cessantes; o dano moral individual compensatório e, ainda, o dano social de caráter punitivo "por ter o autor agido com dolo ou culpa grave, ou como dissuasão, para não levar à repetição, pelo agente ou por outros, dos mesmos atos. A indenização, qualquer que seja, deverá ser entregue à própria vítima" (AZEVEDO, 2004, p. 383).

Ou seja, tem-se que o destinatário do dano social deveria ser a vítima que propôs a ação e não a sociedade lesada (através de um Fundo de Direitos Difusos, por exemplo), quando em ação individual. Algo como um acréscimo ao dano moral ou material já estabelecido, pela conduta reprovável do agente. 
No entanto, dada à dupla perspectiva - da vítima e do ato ilícito, entende-se que a parcela da vítima é ressarcitória e já a compensa pelos danos sofridos. Agora, a perspectiva do ato ilícito não visa compensar a vítima, apenas punir o ofensor, como visto. Por que, então, justificar-se-ia atribuir seu valor destinando-o à vítima?

Segundo o autor, assim o seria, pois, o Ministério Público já tem funções demais e se tornaria "irreal" relegar mais um dever ao Estado - de participar da ação para que o valor tenha como destinatário um fundo (AZEVEDO, 2004, p. 383), e, portanto, a sociedade como um todo, ao invés de uma única vítima.

Esta não é, contudo, a posição que será tomada nesse trabalho. Pelo contrário, essa ideia será rebatida no item seguinte para dissociação da ideia do dano social para a vítima - considerada aqui como destinatário impróprio do dano difuso.

Esse posicionamento corrobora com julgado emblemático de 2007, do Tribunal de Justiça do Rio Grande do Sul, em recurso cível 71001281054, no qual determinou, de ofício, indenização a título de dano social para o Fundo de Proteção aos Consumidores, e não à vítima autora da ação, constatada fraude ocorrida em um sistema de loterias do estado, retirando do consumidor as chances de vencer ${ }^{10}$.

Assim, os chamados "novos danos" demonstram a perspectiva crescente da punição do ato ilícito, além da mera restituição à vítima, para a ampla reparação civil.

\section{RELEITURA AO DANO SOCIAL NAS RELAÇÕES DE CONSUMO}

\footnotetext{
${ }^{10}(\ldots)$ "sistema de loterias de chances múltiplas. fraude que retirava ao consumidor a chance de vencer. ação de reparação de danos materiais e morais. danos materiais limitados ao valor das cartelas comprovadamente adquiridas. danos morais puros não caracterizados. Possibilidade, porém, de excepcional aplicação da função punitiva da responsabilidade civil. na presença de danos mais propriamente sociais do que individuais, recomenda-se o recolhimento dos valores da condenação ao fundo de defesa de interesses difusos". 2. Ausência de danos morais puros (...). 3. Presença de fraude, porém, que não pode passar em branco. Além de possíveis respostas na esfera do direito penal e administrativo, o direito civil também pode contribuir para orientar os atores sociais no sentido de evitar determinadas condutas, mediante a punição econômica de quem age em desacordo com padrões mínimos exigidos pela ética das relações sociais e econômicas. Trata-se da função punitiva e dissuasória que a responsabilidade civil pode, excepcionalmente, assumir, ao lado de sua clássica função reparatória/compensatória. "O Direito deve ser mais esperto do que o torto", frustrando as indevidas expectativas de lucro ilícito, à custa dos consumidores de boa-fé. 4. Considerando, porém, que os danos verificados são mais sociais do que propriamente individuais, não é razoável que haja uma apropriação particular de tais valores, evitando-se a disfunção alhures denominada de overcompensantion. Nesse caso, cabível a destinação do numerário para o Fundo de Defesa de Direitos Difusos, criado pela Lei 7.347/85, e aplicável também aos danos coletivos de consumo, nos termos do art. 100, parágrafo único, do CDC. Tratando-se de dano social ocorrido no âmbito do Estado do Rio Grande do Sul, a condenação deverá reverter para o fundo gaúcho de defesa do consumidor. (...) BRASIL, Tribunal de Justiça do Rio Grande do Sul. Recurso cível 71001281054.
}

Revista de Direito, Globalização e Responsabilidade nas Relações de Consumo | e-ISSN: 2526-0030 | Salvador | v. 4 | n. 1 | p. 01 - 20 | Jan/Jun. 2018 
Superada a diferenciação entre as espécies de tutelas coletivas de direito como posta no Código de Defesa do consumidor: em difusa, coletiva stricto sensu e individual homogênea, passaremos a analisar situações classificadas doutrinariamente como "situações jurídicas heterogêneas" (ZAVASCKI, 2008, p. 44-45). São estas emergentes da complexidade das relações vivenciadas na contemporaneidade, a ponto de não ser possível classifica-las com segurança a uma categoria jurídica de tutela específica, ignorando as demais.

Desta maneira, uma mesma situação pode ensejar no interesse de ser tutelada de forma coletiva, enquanto direito transindividual, ou enquanto direito individual homogêneo. $\mathrm{Ou}$, ainda, de forma individual. Isto, pois, os acontecimentos geradores de danos têm caráter múltiplos, não homogêneos, e podem transpassar entre as diferentes ferramentas disponíveis conforme a perspectiva do interesse a ser tutelado.

Em caráter elucidativo, pode-se, figurativamente, trazer o seguinte exemplo: um fabricante de leites em embalagem longa-vida coloca no mercado produto com alto grau de contaminação por produto tóxico. Em um primeiro momento imagina-se o interesse da tutela difusa ao caso, ao impor uma sanção de retirada do mercado do produto. Não seria possível, no entanto, determinar os prejudicados, pelo contrário, pela natureza da tutela difusa, como visto anteriormente, toda a sociedade seria beneficiada por ter sua saúde e integridade física preventivamente preservada.

Por outro lado, de uma classe também poderia emergir o interesse na tutela coletiva, porém de forma estrita. Neste caso, os demais produtores de leite do Brasil poderiam mover ação coletiva no sentido de resguardar a credibilidade da categoria, com uma sanção de contrapropaganda às notícias negativas geradas pelo ocorrido.

Não impediria, também, que os consumidores que efetivamente tiveram sua saúde comprometida com o consumo quisessem ingressar em juízo, através da tutela coletiva de direitos individuais homogêneos, visando a reparação ao caso específico. Ou, ainda, que optassem pela vida individual para tanto.

Como visto, de um mesmo ato ilícito - colocação no mercado de produto nocivo (art. $8^{\circ}, \mathrm{CDC}$ ), nasceram diferentes interesses de proteção de direitos, sem que uma tivesse o condão de excluir ou negar as demais.

A existência de situações dessa jaez, que fogem dos padrões conceituais rígidos, de modo algum infirma as distinções antes 
empreendidas, nem desautoriza o esforço metodológico que se deve desenvolver no trato doutrinário da matéria. Quando as peculiaridades do fato concreto não podem ser subsumidas direta e imediatamente nos gêneros normativos existentes nem submetidas aos padrões conceituais pré-estabelecidos, cumprirá ao aplicador da lei a tarefa de promover a devida adequação, especialmente no plano dos procedimentos, a fim de viabilizar a tutela jurisdicional mais apropriada para o caso. Também o domínio do processo coletivo, que, como todo processo, tem vocação essencialmente instrumental, há de imperar o princípio da adequação das formas: o instrumento deve ser amoldado para servir a seus fins (ZAVASCKI, 2008, p. 46).

É, portanto, apenas a partir do caso concreto que se pode optar qual tutela estará mais próxima de efetivar os direitos que se destinam ou por cumulá-las.

E ainda, por expressa previsão legal (art. 83, CDC), admite-se toda e qualquer espécie de ação na tutela de direitos coletivos, umas sem prejuízo da outra. Não há dúvidas, portanto, do caráter heterogêneo do direito nem da possibilidade de cumulação de tutelas coletivas e individualizadas.

Seria preciso, no entanto, um tipo de ação para cada tutela pretendida ou elas podem dar ensejo de um único movimento processual? Uma ação de direitos individuais homogêneos poderia cumular um pedido de retirada do mercado de determinado produto ou uma multa inibitória/preventiva de caráter difuso? Há, de fato, como separar claramente cada pretensão sem ferir a completude da reparação de danos almejada? A aplicação de multa não é sempre uma tutela difusa?

Pretende-se, nessa etapa, buscar a caracterização do Dano Social, de caráter difuso, como viável de aplicação não apenas na esfera de defesas coletivas, mas também individuais, para a viabilização do dano social reparativo e preventivo em prol da sustentabilidade.

Para tanto, faz-se a necessária limitação do "dano social" como posto nesse trabalho, que se aproxima da trazida por Azevedo (2004, p. 370-377), como sendo um novo tipo de dano, acrescido às categorias de dano moral, dano material e dano estético já consolidadas.

No entanto, apesar de utilizar o conceito já formado de "dano social" enquanto direito material, utilizar-se-á, neste trabalho, o termo para aplicação também em tutela individual do interesse difuso social - com destinação ao Fundo de Direitos Difusos, e não à 
vítima direta - como ficará melhor explicitado no item seguinte.

\subsection{O dano social em esfera de tutela de direito individual de consumo}

O que se pretende, a partir desta parte, é destacar o caráter metaindividual e a tutela difusa do Dano Social também nas ações individuais de consumo. Isto pois, ainda que

(...) a tutela coletiva (especialmente em nível preventivo) deva assumir caráter preferencial, já que possui a incensurável virtude de minimizar uma série de efeitos colaterais mais problemáticos da tutela jurisdicional individual na esfera dos direitos a prestações sociais, também é certo - de acordo com o que se extrai da decisão do STF (...), que assegurou o fornecimento de medicamento de alto custo em demanda individual promovida pelo Ministério Público Federa, - que a eliminação da possibilidade de demandas individuais poderá, por si só, representar uma violação de direitos fundamentais, (...) quando não assegurado um patamar suficiente de proteção social (SARLET, 2015).

Ou seja, a tutela individual, em determinadas hipóteses, pode ser a maneira mais adequada para a proteção e promoção do direito dadas suas especificidades, ainda que pertença a uma coletividade de pessoas atingidas pelo mesmo fato gerador.

Delimitar-se-á, para tanto, a aplicação dos danos sociais em esfera de ação individual de consumo para a tutela dos direitos difusos que atinjam, de alguma, particularmente um consumidor que sofre dano concreto com a prática que atinge também um grupo indeterminável.

Nesse sentido, um dano não perde seu caráter difuso por estar sendo tutelado em esfera individual. A publicidade abusiva ou enganosa, a segurança alimentar e o direito à informação, a responsabilidade do fornecedor de produção em massa e a tão conhecida obsolescência programada são alguns exemplos.

A indenização por dano moral, em âmbito jurisdicional brasileiro, tem clara natureza pedagógica e punitiva, sendo esta última, muitas vezes, seu objetivo maior: servir de desestímulo para a repetição da conduta. Visam, portanto, não só aplacar a dor, o sofrimento e a angústia, mas tem, em si, além da compensação pecuniária, caráter de pena. Procuram tanto a perspectiva da vítima, ao ressarci-la, quanto do transgressor, ao desencorajá-lo da prática (GEOGIARDES, 2005). 
Esta penalização pedagógica, imposta ao ofensor do mercado de consumo, deveria impingi-lo a um prejuízo proporcionalmente maior do que as vantagens obtidas com aquele ato ilícito, ou estar-se-ia incentivando uma reincidência baseada na impunidade.

O sistema jurídico brasileiro já admite o dano punitivo, todavia, seu destinatário, como posto, é impróprio. Isto pois, além da parte ressarcitória, que é claramente em benefício da vítima; a parcela punitiva, que segue a perspectiva do infrator, agrupa-se no mesmo montante de "dano moral". E ao fazê-lo, perde-se o parâmetro do quantum a ser arbitrado, ora de forma excessiva - na vontade de punir a conduta ilícita, ora de forma ínfima - em tentativa de não haver o enriquecimento sem causa, sem existência de uniformidade em sua valorização.

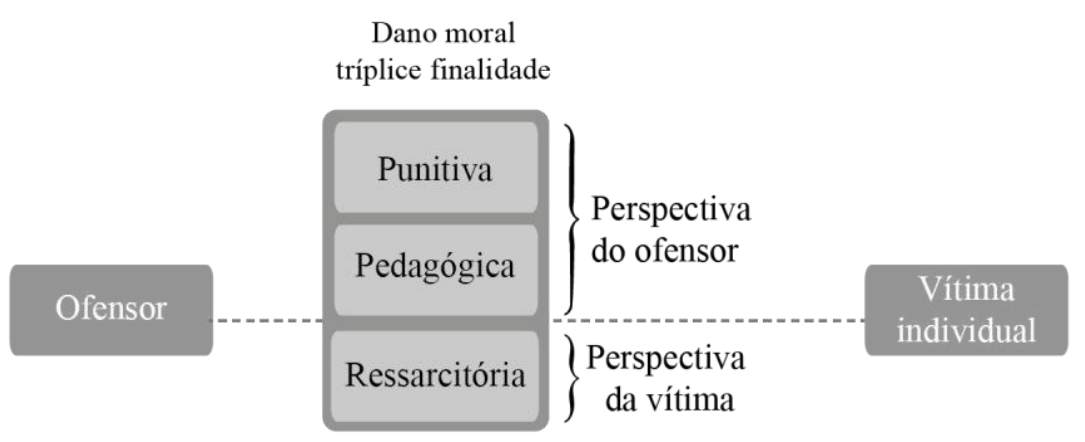

FIGURA 1: A tríplice finalidade do dano moral como aplicada pelo judiciário brasileiro atualmente.

FONTE: Os autores (2017)

Quando da ação individual que tutela um direito metaindividual, entende-se que a única parcela devida ao consumidor vítima é a ressarcitória, a fim de lhe elevar ao status quo pretendido. Desta maneira, a valorização recairia unicamente sobre as condições da vítima e seu patrimônio moral.

Já a parcela punitiva revela-se tendo como destinatário toda a coletividade direta e indiretamente atingida pelo dano ao direito metaindividual, representando, então, o "dano social". Estaria suprimida a dúvida quanto ao enriquecimento sem causa, já que o consumidor individual não seria excessivamente beneficiado, além da sua reparação pretendida. 


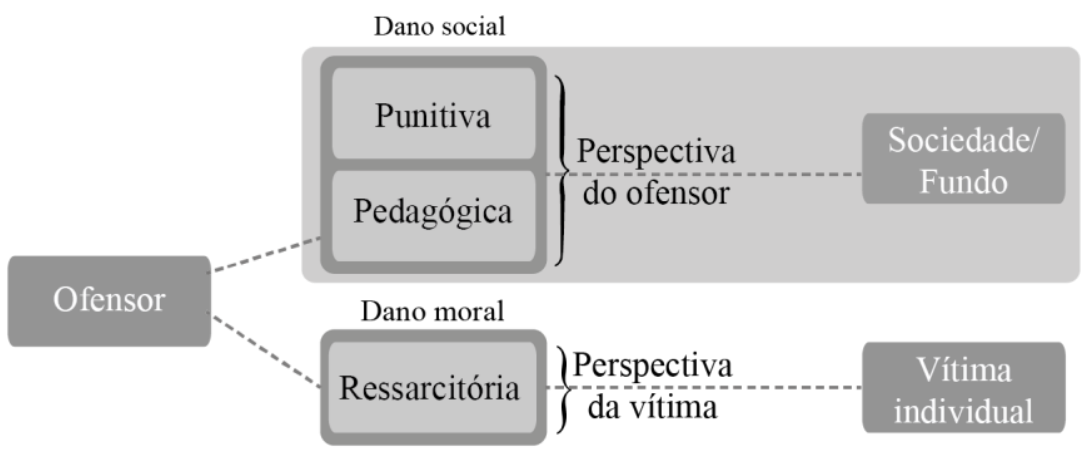

FIGURA 2: A divisão da finalidade dos danos como proposta pelo trabalho

FONTE: Os autores (2017)

Da mesma forma, sendo um dano passível de responsabilidade objetiva, não obstaria a aplicação do dano social, sendo especialmente reprovável sua conduta, diferenciando de situação similar em que houvesse, diferentemente, tomados os cuidados necessários, e, ainda assim, não suficientes para evitar o dano - o qual ensejaria apenas os danos reparatórios. Isto pois, a responsabilidade objetiva “(...) não 'eliminou do mapa' a responsabilidade subjetiva: esta continua a atuar em todas as brechas em que não cabe responsabilidade objetiva e, além disso, pode ser cumulada como causa de indenização nos casos de responsabilidade objetiva (AZEVEDO, 2004, p. 380).

Por terem funções distintas, a punição ao infrator que comete um ilícito de caráter difuso deveria ser dividida entre ressarcitória e punitiva para que, esta última, tivesse destinação para o Fundo de Defesa de Direitos Difusos, ou fundo próprio de consumidor. Desta maneira, estar-se-ia retornando à coletividade o que dela foi usurpado pelo ato contrário à boa-fé objetiva que se espera das relações de consumidor.

Da mesma maneira o impasse entre o enriquecimento ilícito sem incentivar as más práticas pela irrisória punição do ofensor, estaria solucionado. O consumidor não receberia mais do que se prejulga devido, e o ofensor, de outro modo, poderia ter uma punição mais severa, de acordo com a sua conduta, já que tal valor não levaria ao enriquecimento de ninguém, senão da sociedade, através da aplicação do "dano social".

Espera-se, assim, do judiciário, não mais apenas a satisfação do dano individual. Pois, se há uma comunhão indivisível representada pelo direito difuso, a satisfação de um é a de todos, bem como a lesão de direito também pertence à coletividade.

Neste sentido, a jurisprudência brasileira encontrou algumas alternativas para 
aplicabilidade do "dano social" aqui retratado, ainda que com outras nomenclaturas, tanto em tutelas coletivas, como nas tutelas individuais. Alguns estados encontraram uma alternativa para a aplicabilidade da multa civil administrativa, em esfera judicial, a fim de reverter o valor da punição do ofensor ao Fundo de Direitos Difusos. Esta previsão está contida no Código de Defesa do Consumidor, nos artigos $56^{11}$, o qual admite expressamente a aplicação de sanção civil e no artigo $57^{12}$, cuja sanção administrativa tem limite máximo.

Juízes utilizam-se deste recurso $^{13}$ (TRIBUNAL DE JUSTIÇA DE SANTA CATARINA), no qual o consumidor receberia sua devida indenização, dentro dos moldes atuais de valoração, enquanto o ofensor, de outro modo, pagaria, além da indenização, uma multa civil aos cofres públicos ou fundos de direitos difusos, como forma de desestimular a prática repetitiva da conduta.

Apesar de o destinatário do dano social, conceituada anteriormente, ser também a sociedade, através dos fundos de direito, difere-se da mera multa por se tratar de "novo tipo de dano" que não busca apenas ampliar quantitativamente a valoração, mas retirar o caráter punitivo do dano moral e delegá-lo à coletividade.

Nos acórdãos do Tribunal de Justiça de Santa Catarina há decisão de $2004^{14}$, cujo relator justifica que, "se o critério para alcançar o valor da reparação passa pela punição do infrator e pela compensação do ofendido, nada mais justo do que na parte dispositiva da sentença também separar indenização e punição, evitando enriquecimento indevido".

Seria ainda possível aplicar a sanção de ofício, "com o intuito de concretizar a efetiva repressão de que trata o art. $6^{\circ}$, VI, do $\mathrm{CDC}$, bem como em atenção à proteção constitucional conferida ao consumidor e ao mercado de consumo no art. $5^{\circ}$, XXXII e art. 170

\footnotetext{
${ }^{11}$ Art. 56. As infrações das normas de defesa do consumidor ficam sujeitas, conforme o caso, às seguintes sanções administrativas, sem prejuízo das de natureza civil, penal e das definidas em normas específicas: I multa [...];

${ }^{12}$ Art. 57. A pena de multa, graduada de acordo com a gravidade da infração, a vantagem auferida e a condição econômica do fornecedor, será aplicada mediante procedimento administrativo, revertendo para o Fundo de que trata a Lei $\mathrm{n}^{\circ} 7.347$, de 24 de julho de 1985, os valores cabíveis à União, ou para os Fundos estaduais ou municipais de proteção ao consumidor nos demais casos.

13 Apelação cível n. 2012.003232-7, de Sombrio, relator Des. Fernando Carioni, julgado em 28/02/2012 e apelação cível n. 2012.001050-3, de São Bento do Sul, relator Desembargador Francisco Oliveira Neto, julgado em 07/08/2012.

${ }^{14}$ Apelação cível n. 03.018286-1, de Criciúma, relator Desembargador José Volpato de Souza, julgado em 18/06/2004.
}

Revista de Direito, Globalização e Responsabilidade nas Relações de Consumo | e-ISSN: 2526-0030 | 
da CRFB, respectivamente" ${ }^{\text {15 }}$.

A prática da aplicação do chamado "dano social" pelos juizados especiais, principalmente pelo Tribunal de Justiça de Goiás, levou a controvérsia ao Superior Tribunal de Justiça (STJ), que, em recente decisão, decidiu firmar sua posição de julgamento extra petita. Sendo, portanto, nula a decisão que condena a parte ré, de ofício, em ação individual, ao pagamento de indenização a título de danos sociais em favor de terceiro que não faz parte do processo $^{16}$. Ainda no mesmo julgado, considerou-se que, mesmo havendo pedido de condenação em danos sociais, não poder-se-ia acatar o pleito por ausência de legitimidade. $\mathrm{O}$ pleito aos danos sociais, portanto, seriam aceitos exclusividade das demandas coletivas ${ }^{17}$.

No entanto, tendo a defesa dos interesses e direitos dos consumidores caráter difuso, e sendo garantida em juízo individualmente, ou a título coletivo, como expresso no artigo 81 do $\mathrm{CDC}^{18}$, seria desnecessário ajuizar ação coletiva para imposição da sanção, como salientou Grinover (2009, P. 130):

é certo que os direitos coletivos (lato sensu) gozam de instrumentos processuais específicos de proteção: Lei da Ação Civil Pública, Mandado de Segurança coletivo, Ação popular, Ação de Improbidade Administrativa. Mas é certo também que, por intermédio de uma demanda individual, podem ser protegidos direitos e interesses coletivos lato sensu.

Justificado também pelo artigo 83, do CDC, no qual permite-se "todas as espécies de ações capazes de propiciar sua adequada e efetiva tutela" para a defesa dos direitos do consumidor". Há de se lembrar da renovação processual, vista anteriormente pela relativização dos princípios contratuais, fundada na proteção integral do consumidor em diversas áreas, bem como o caráter público da lei consumerista, que autoriza o juiz, com uso da equidade, a adequar a aplicação da lei ao caso concreto de forma a propiciar maior

\footnotetext{
15 Apelação cível n. 2010.020330-8, de São Bento do Sul, relator Des. José Volpato de Souza, julgado em $16 / 07 / 2010$.

${ }^{16}$ BRASIL, Superior Tribunal de Justiça. Reclamação n. 12.062: GO (2013/0090064-6), relato: Ministro Raul Araújo, julgado em 18/12/2013.

${ }^{17}$ Em consonância com o Enunciado 455 da V Jornada de Direito Civil do CJF/STJ: "A expressão 'dano' no art. 944 abrange não só os danos individuais, materiais ou imateriais, mas também os danos sociais, difusos, coletivos e individuais homogêneos a serem reclamados pelos legitimados para propor ações coletivas"

${ }^{18}$ Art. 81. A defesa dos interesses e direitos dos consumidores e das vítimas poderá ser exercida em juízo individualmente, ou a título coletivo. Parágrafo único. A defesa coletiva será exercida quando se tratar de: I interesses ou direitos difusos, assim entendidos, para efeitos deste código, os transindividuais, de natureza indivisível, de que sejam titulares pessoas indeterminadas e ligadas por circunstâncias de fato.
} 
proximidade à justiça.

As atuais relações massificadas ensejam um repensar das práticas processuais. A fixação de limites técnicos ao julgamento da causa e seus pedidos não correspondem às expectativas da Constituição Cidadã e dos Direitos Sociais.

A grande maioria dos litígios consumeristas tem relevância para um grande número de pessoas, que muitas vezes permanecerão estranhas à ação e aos efeitos do julgado pela interpretação dada a regra clássica processual, segundo a qual a sentença só é vinculante àqueles do polo ativo e passivo e aos limites dos pedidos da ação (CPC, 2015) ${ }^{19}$.

\section{CONSIDERAÇÕES FINAIS}

Ainda que as Ações Civis Públicas tutelem direitos coletivos, difusos ou individuais homogêneos, sua representação não pode ser feita em caráter individual pelo consumidor e dividem, doutrinaria e jurisprudencialmente, os danos causados ao consumidor como individual ou ao mercado de consumo, como se houvesse, de fato, uma negativa do segundo quando do primeiro.

$\mathrm{O}$ que aqui se pretendeu é trazer à satisfação da lesão individual o reaparelhamento social, através do Fundo de Defesa de Direitos Difusos, necessário para uma efetiva mudança de conduta no mercado como um todo.

A separação dos critérios embasadores do dano moral, qual seja ressarcitório e punitivo/pedagógico, dá a oportunidade de reequilibrar o difícil dilema do enriquecimento ilícito versus indenização não exemplar, a fim de que o primeiro tenha destinatário próprio: a própria sociedade lesada.

Para auxiliar na construção de doutrina capaz de convencer o Magistrado brasileiro a dissociar o caráter punitivo do ressarcitório do dano, para que o valor do primeiro seja destinado à sociedade e apenas o segundo ao indivíduo, é necessário que o Código de Defesa do Consumidor seja interpretado no viés social que exige a Constituição da República Federal do Brasil. Para, enfim afastar o enriquecimento injusto, mas garantir a ampla reparação da sociedade lesada.

\footnotetext{
${ }^{19}$ art. 17: "Para postular em juízo é necessário ter interesse e legitimidade".
} 
Assim, responde-se que o Dano Social, enquanto tutela de direito difuso, ainda que em uma ação individual de consumo, tem o objetivo de reequilíbrio das relações consumeristas através de duas ideias: a primeira de que a parte punitiva/pedagógica da fundamentação do dano não deve ter destinatário final uma única vítima, e sim toda a sociedade lesada, possibilitando valores altos sem o receio do enriquecimento indevido da vítima; e a segunda de que a vítima deveria receber apenas a parcela reparadora do dano à ela causado, evitando assim a procura pelo judiciário com propósito de "aventura jurídica".

\section{REFERÊNCIAS DAS FONTES CITADAS}

AZEVEDO, Antonio Junqueira de. Por uma nova categoria de dano na responsabilidade civil: o dano social. In: Filomeno, José Geraldo Brito; Wagner Júnior, Luiz Guilherme da Costa; Gonçalves, Renato Afonso (Coord.). O código civil e sua interdisciplinaridade. Belo Horizonte: Del Rey, 2004.

BARROS, Sérgio Resende. Direito do consumidor e gerações de direitos. Disponível em <http://www.srbarros.com.br/pt/direito-do-consumidor-e-geracoes-de-direitos.cont> Acesso em 15 de janeiro de 2018.

BITTAR FILHO, Carlos Alberto. Do dano moral coletivo no atual contexto jurídico brasileiro. In Revista de direito do consumidor, vol. 12, São Paulo: Editora Revista dos Tribunais, 1994.

BONAVIDES, Paulo. Curso de direito constitucional. 19. ed. São Paulo: Editora Malheiros, 2006.

BRASIL. Código de defesa do consumidor. Lei n. 8.078 de 1990. Disponível em <http://www.planalto.gov.br>. Acesso em 10 de janeiro de 2018.

BRASIL. Código de processo civil. Lei n.13.105 de 2015. Disponível em <http:/ /www.planalto.gov.br >. Acesso em 10 de janeiro de 2018.

BRASIL. Constituição da República Federativa do Brasil. Brasília, DF: Senado, 1988.

BRASIL. Política nacional do meio ambiente. Lei n. 6.938 de 1981. Disponível em <http:/ /www.planalto.gov.br >. Acesso em 10 de janeiro de 2018.

CAPPELLETTI, Mauro; CARTH, Bryant. Acesso à justiça. Porto Alegre, Rio Grande do Sul: Sérgio Antônio Fabris, 1998.

CNJ. Justiça em números: 2017, ano base 2016. Disponível < http://cnj.jus.br/files/conteudo/arquivo/2017/12/b60a659e5d5cb79337945c1dd137496c.pdf>. Acesso em 29 de outubro de 2017.

PASOLD, Cesar Luiz. Metodologia da pesquisa jurídica: teoria e prática. 12 ed. rev. São Paulo: Conceito Editorial, 2011.

GEORGIADES, Georgios. Punitive damages in Europe and the USA: doctrinal differences and practical convergence. Revue Hellenique de Droit International, 2005. 
GIDI, Antônio. Coisa julgada e litispendência em ações coletivas. São Paulo: Saraiva, 1995.

GRINOVER, Ada Pellegrini. O controle de políticas públicas pelo Poder Judiciário. Porto Alegre: TRF - $4^{\text {a }}$ Região, 2009. Caderno de Administração da Justiça: planejamento estratégico 2009: módulo 6.

GRINOVER, Ada Pellegrini. Os processos coletivos nos países de civil law e common law: uma análise de direito comparado. São Paulo: RT, 2008.

LEITE, José Rubens Morato. Dano ambiental: do individual ao coletivo extrapatrimonial. São Paulo: Revista dos Tribunais, 2000.

MEDEIROS NETO, Xisto Tiago de. Dano moral coletivo. 2. ed. São Paulo: LTr, 2007.

PLUTARCO, Hugo Mendes. A sonegação e a litigância tributária como forma de financiamento. Economic analysis of law review, v. 3, n. 1, jan-jun 2012. Disponível em https://portalrevistas.ucb.br/index.php/EALR/article/view/3\%20EALR\%20122/3\%20EALR\% 20122. Acesso em 10 de janeiro de 2018.

SARLET, Ingo Wolfgang. A titularidade simultaneamente individual e transindividual dos direitos sociais analisada à luz do exemplo do direito à proteção e promoção da saúde.

Revista Páginas de Direito, Porto Alegre, ano 15, $\mathrm{n}^{\circ}$ 1240, 12 de maio de 2015. Disponível em: http://www.tex.pro.br/artigos/305-artigos-mai-2015/7129-a-titularidade-

simultaneamente-individual-e-transindividual-dos-direitos-sociais-analisada-a-luz-doexemplo-do-direito-a-protecao-e-promocao-da-saude-1. Acesso em 30 de outubro de 2017.

ZAVASCKI, Teori Albino. Processo coletivo: tutela de direitos coletivos e tutela coletiva de direitos. São Paulo: RT, 2008.

ZAVASKI, Teori Albino. Defesa de direitos coletivos defesa coletiva de direitos. Revista de Processo, v. 20, n. 78, p. 32-49, abr./jun. 1995. 